\section{Caminhos para viabilização da convergência de interesses na despoluição do Rio Guandu, Rio de Janeiro, Brasil}

\author{
Paths to convergence of interests in depollution \\ of the Guandu River in Rio de Janeiro, Brazil
}

\author{
Caminos para hacer viable la convergencia \\ de intereses en la descontaminación del \\ Río Guandú, Río de Janeiro, Brasil
}

Debora Cynamon Kligerman 1
Sandra Novellino Sancanari 2
Joseli Maria Rocha Nogueira 1

doi: 10.1590/0102-311X00234420

\section{Resumo}

Em janeiro de 2020, a população da Região Metropolitana do Rio de Janeiro, Brasil, foi submetida a uma deterioração da qualidade da água, causada pela presença de geosmina, que comprometeu o processo de tratamento de água da Estação de Tratamento de Água do Guandu, único manancial desta região. Esse fenômeno é consequência da falta de investimento em esgotamento sanitário ao longo da bacia do Rio Guandu, que antes afetava apenas a população predominantemente de baixa renda. Este artigo objetiva identificar o papel e a atuação dos diferentes atores sociais, por meio da adoção da metodologia de Integração Sistêmica, para viabilizar a convergência de interesses destes atores no sentido de priorizar e concretizar a despoluição do Rio Guandu. Foram segregados dois grupos: aqueles que devem trabalhar articuladamente para o sucesso do empreendimento, composto por todos os órgãos de planejamento, operação, regulação e fiscalização, e os atores capazes de alavancar politicamente e viabilizar sua realização, que são os influentes setores sociais, políticos, econômicos e midiáticos. Chegou-se ao entendimento de que a crise de abastecimento de água pode se repetir sazonalmente caso nada seja feito, podendo este ser o elemento capaz de prover a nunca antes alcançada convergência de interesses dos setores influentes para realizar o investimento em infraestrutura de esgotamento sanitário que reverta a degradação da bacia, requisito para resolver a crise de água no Rio de Janeiro.

Abastecimento de Água; Estações de Tratamento de Água; Redes de Esgoto; Politicas Públicas; Projetos de Investimento Social

\author{
Correspondência \\ D. C. Kligerman \\ Departamento de Saneamento e Saúde Ambiental, Escola \\ Nacional de Saúde Pública Sergio Arouca, Fundação Oswaldo \\ Cruz. \\ Rua Leopoldo Bulhões 1480, 5a andar, Rio de Janeiro, RJ \\ 21041-210, Brasil. \\ deboracyklig@gmail.com \\ 1 Escola Nacional de Saúde Pública Sergio Arouca, Fundação \\ Oswaldo Cruz, Rio de Janeiro, Brasil. \\ 2 Federação das Indústrias do Estado do Rio de Janeiro, Rio de \\ Janeiro, Brasil.
}




\section{Introdução}

No início de 2020, a população da Região Metropolitana do Rio de Janeiro, Brasil, foi surpreendida com uma crise no abastecimento de água, tendo sido observadas alterações em seu odor, sabor, turbidez e coloração. Essas alterações ocorreram devido à proliferação de algas e da substância geosmina 1,2. Produzida a partir de bactérias filamentosas (Actinomycetos) no solo e por algas verde-azuladas (cianobactérias) em ambientes aquáticos, a geosmina está ligada ao odor de terra molhada, ao cheiro de mofo e ao gosto terroso em alimentos e na água 3.

Esta tragédia poderia ter sido prevista, já que o Rio Guandu e seus afluentes (rios Queimados, Poços e Ipiranga), localizados na Baixada Fluminense, recebem, dos quinze municípios localizados na bacia do Rio Guandu, 112 milhões de litros de esgotos domésticos in natura por dia 4 . Como o esgoto possui nitrogênio e fósforo, e com a presença de luz, além de calor, o ambiente se torna propício para o surgimento de algas 5 .

A Estação de Tratamento de Água do Guandu (ETA Guandu), inaugurada em 1955, é a maior estação de tratamento de água do mundo em produção contínua, com vazão de 43 mil litros por segundo. É gerida pela Companhia Estadual de Águas e Esgotos (CEDAE - https://www.cedae.com.br/estacoes_tra tamento, acessado em 27/Mar/2020), empresa pública que detém a responsabilidade pelo saneamento básico de 64 municípios no Estado do Rio de Janeiro.

Como ao longo dos anos não foram implantadas redes de coleta e estações de tratamento nos municípios ao longo do Rio Guandu, serviços delegados à CEDAE, a empresa se limitou a divulgar que, desde 2009, possui um projeto de obra emergencial que consiste na construção de um dique associado a outras estruturas hidráulicas a fim de impedir a chegada de esgoto dos afluentes do Rio Guandu na lagoa de captação da estação de tratamento 6 . Esse projeto, orçado na época em BRL 33 milhões, foi engavetado em 2009, com a alegação de que seria necessário um acréscimo de BRL 50 milhões no orçamento original e que, de toda forma, essa obra estaria inserida no Programa de Aceleração do Crescimento 7 .

O simples desvio do esgoto, no entanto, não é a solução do problema. Somente com a coleta e tratamento do esgoto nos municípios ao longo da bacia hidrográfica do Rio Guandu esse problema estará resolvido. Em teoria, esse conceito está bem estabelecido, mas sabe-se que, como em todo o Brasil, obras de saneamento para populações de baixa renda têm, na prática, baixa prioridade e pouca abrangência 8 .

Com base no exposto, este artigo apresenta uma análise da crise do abastecimento de água do Rio de Janeiro e utiliza a metodologia de Integração Sistêmica. O objetivo é identificar o papel e a atuação dos diferentes atores sociais para viabilizar a convergência de seus interesses no sentido de priorizar e concretizar a despoluição do Rio Guandu.

$\mathrm{O}$ artigo se inicia com a descrição da bacia e, em seguida, a evolução dos principais problemas ambientais e as ações até então realizadas, insuficientes para diminuir a degradação da bacia. Como proposta de solução, é descrita a metodologia de Integração Sistêmica, que, para o problema em questão, mapeia dois grupos de atores sociais: um que pode mobilizar a sociedade a exigir a solução para a degradação ambiental e o outro que tem o poder de planejar e operacionalizar as ações para o controle da poluição da bacia do Rio Guandu, considerando que este controle também evitaria a repetição da crise no abastecimento de água do Rio de Janeiro. A seguir, são apresentados os setores relacionados ao processo de despoluição do Rio Guandu e sugeridos os caminhos que podem ser trilhados para a convergência de interesses.

\section{Descrição da bacia hidrográfica do Rio Guandu}

A bacia hidrográfica do Rio Guandu abrange 15 municípios e possui $1.395 \mathrm{~km}^{2}$. O rio possui $48 \mathrm{~km}$ de extensão e deságua na Baía de Sepetiba, sendo formado predominantemente pelo encontro dos rios Santana, Ribeirão das Lages e Queimados, tendo ainda como importantes tributários os rios São Pedro, Poços e Ipiranga 9 (Figuras 1 e 2). 
Figura 1

Bacia hidrográfica do Rio Guandu.
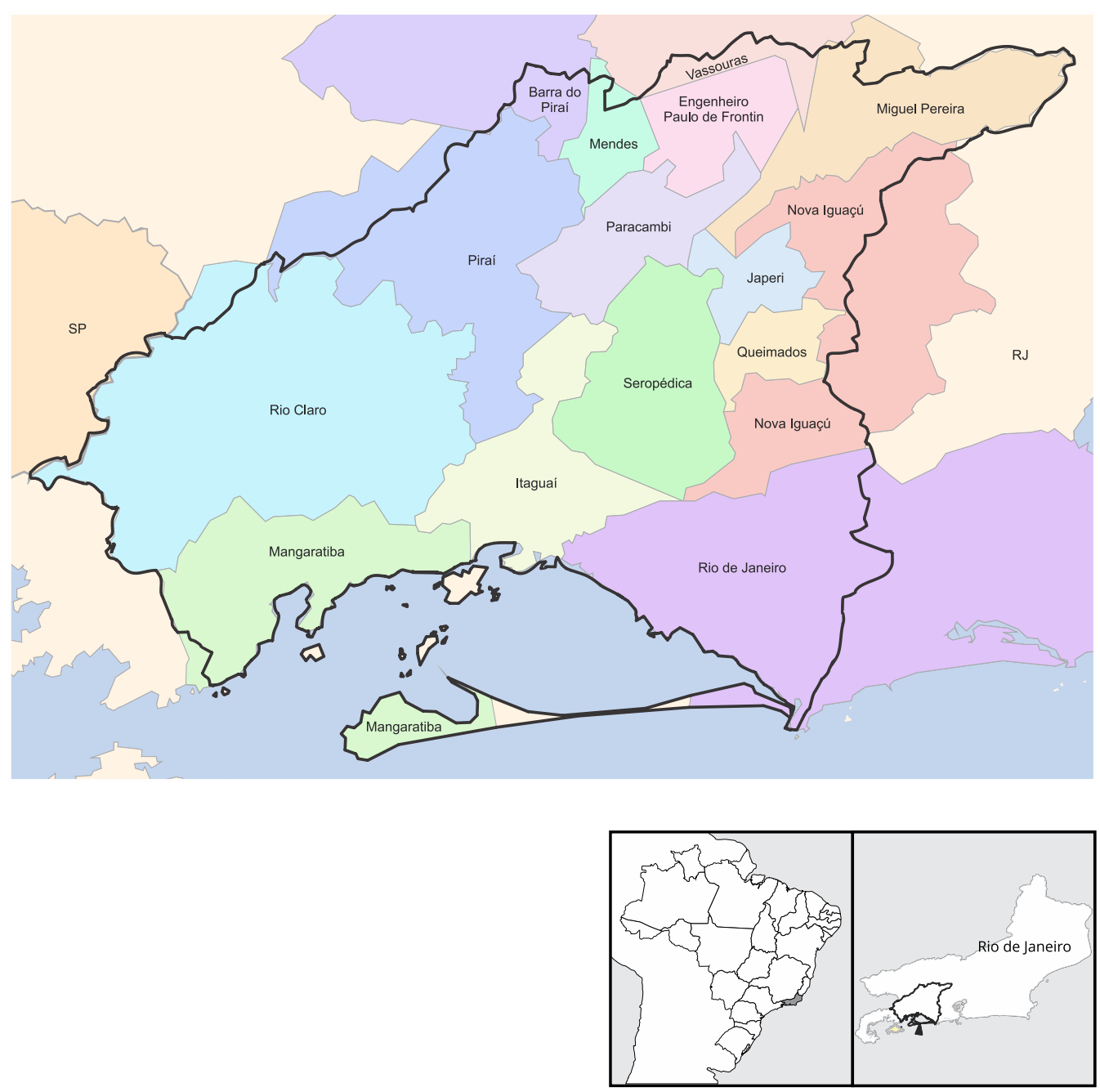

\section{Legislação ambiental}

A coordenação geral das ações relacionadas a recursos hídricos foi materializada no ano de 2000 com a criação da Agência Nacional de Águas e Saneamento Básico (ANA) 10, entidade federal responsável pela implementação da Política Nacional de Recursos Hídricos e coordenação do Sistema Nacional de Gerenciamento de Recursos Hídricos.

Ainda que a principal fonte de poluição dos recursos hídricos no país e no Estado do Rio de Janeiro seja a falta de saneamento 11, esse setor só foi regulamentado com a criação, em 2007, da Política Nacional de Saneamento Básico 12. Essa lei somente estabelece as atribuições do titular, sem identificá-lo, uma vez que havia o entendimento de que o titular seria o município, pois a Constituição Federal de 1988 definiu que a instância municipal seria a responsável pelos serviços de interesse local. Recentemente foi aprovado um novo marco legal (Lei no 14.026, de 15 julho de 2020) 13, segundo o qual a titularidade é exercida, no caso de interesse local, pelos municípios e pelo Distrito Federal; no caso 
Figura 2

Hidrograma unifilar da rede hidrográfica do Rio Guandu.

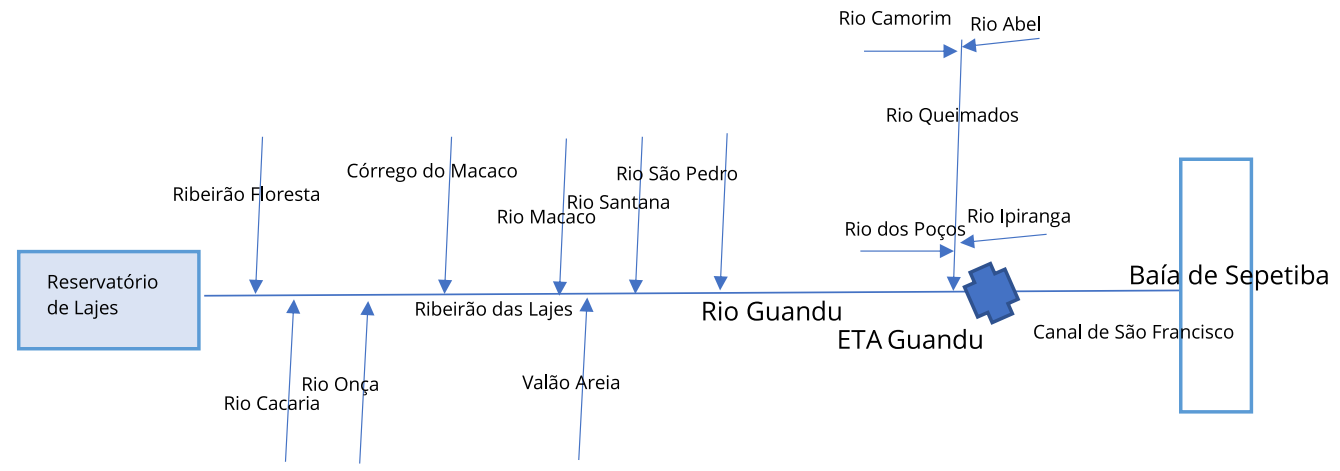

ETA Guandu: Estação de Tratamento de Água do Guandu.

de interesse comum, como de regiões metropolitanas, aglomerações urbanas e microrregiões instituídas por lei complementar estadual, pelo estado em conjunto com os municípios. Além disso, o novo marco legal prevê metas para o abastecimento de água e a coleta e tratamento de esgoto, extinguindo o direito preferencial de empresas estatais e criando um ambiente propício para o aumento dos investimentos privados, atribuindo também à ANA "competência para editar normas de referência sobre o serviço de saneamento" 14 . O Estado do Rio de Janeiro não conta com uma política estadual de saneamento, há apenas o Projeto de Lei no 385, de 4 de junho de 200314.

Em relação aos recursos hídricos, a Política Estadual de Recursos Hídricos (Lei Estadual no 3.239, de 2 de agosto de 1999) 15 tem como instrumentos o Plano Estadual de Recursos Hídricos (PERH), o Programa Estadual de Conservação e Revitalização de Recursos Hídricos (PROHIDRO) e os Planos de Bacia Hidrográfica (PBHs), importantes para o controle da poluição desses recursos no Estado. A cobrança pelo uso dos recursos hídricos, por sua vez, foi instituída pela Lei Estadual no 4.247, de 16 de dezembro de 2003 16, visando a obter recursos financeiros para as intervenções necessárias propostas nos PBHs. Com a poluição crescente do Rio Paraíba do Sul, a Lei Estadual no 4.051, de 30 de dezembro de 2002 17, passou a dispor sobre a criação do programa S.O.S. Rio Paraíba do Sul, objetivando sua revitalização, no que concerne à fiscalização do lançamento de esgoto clandestino e lixo. Também propôs a implantação de melhorias do sistema de esgoto sanitário das comunidades de baixa renda que vivem no entorno do rio.

Em relação ao lançamento de resíduos sólidos em áreas de mananciais e cursos d'água, a Política Estadual de Resíduos Sólidos (Lei Estadual no 4.191, de 30 de julho de 2003) 18 afirma que essa ação é expressamente proibida.

No nível nacional, atualmente, apenas $53,15 \%$ do esgoto é coletado, e somente $46,25 \%$ deste, tratado. No Estado do Rio de Janeiro, esses índices estão abaixo da média nacional, sendo de $50 \%$ e $31,33 \%$, respectivamente 19 . Aparentemente, a legislação, por si só, não é suficiente para concretizar a universalização dos serviços de saneamento. É necessária a vontade política, que emana da mobilização da opinião pública. Nesse sentido, a imprensa tem um papel fundamental ao informar a sociedade sobre a situação atual e, com isso, possibilitar que esta se organize e pressione o poder público para que haja investimento em saneamento. Além disso, é desejável uma forte regulação, o que se constitui em outro grande desafio do setor de saneamento, visto que essa ação depende do fortalecimento e da independência das agências reguladoras.

Com base nesse raciocínio, fica claro que é necessária e fundamental uma adequada conjugação de interesses que despertem a mobilização da sociedade e levem ao consequente direcionamento da orientação política. 


\section{Evolução dos problemas ambientais da bacia do Rio Guandu}

Historicamente, o abastecimento de água para a Região Metropolitana do Rio de Janeiro abarcava desde o uso dos mananciais das serras até os amplos rios que atravessam o estado. Atualmente, o Rio Guandu tem sido a principal opção para este provimento, sendo coadjuvantes o reservatório de Ribeirão das Lajes, o sistema Acari e mananciais locais de pequeno porte ${ }^{20}$. A partir do início do século XX, a vazão do Guandu (Figura 1) foi ampliada com a transposição dos rios Piraí e Paraíba do Sul para geração de energia nas usinas da Light S.A. (empresa privada de geração, distribuição, comercialização e soluções de energia elétrica), passando gradativamente de $25 \mathrm{~m}^{3} / \mathrm{s}$ para $120 \mathrm{~m}^{3} / \mathrm{s} 13$, com o Paraíba do Sul cedendo em média de $60 \%$ de suas águas, que, após a geração de energia, descem pelo Ribeirão das Lajes até juntar-se ao Guandu 11.

Todavia, a ocupação do solo da bacia do Rio Guandu foi sendo modificada e, ao longo dos anos, houve substituição da vegetação de Mata Atlântica, primeiramente pela agricultura e posteriormente para implantação de indústrias, expansão urbana e extração de areia. Atualmente, 67,5\% da área tem uso antrópico relacionado a pastagem (38,3\%), agricultura (17,7\%) e ocupação urbanoindustrial $(11,5 \%)$.

Desde a década de 1970, a poluição da bacia do Rio Guandu vem crescendo, predominantemente devido ao lançamento de efluentes, agravado pelo crescimento industrial e populacional desordenado nos municípios ao longo da bacia. Em menor grau, há um gradativo aumento da poluição do Rio Paraíba do Sul, além de depósitos clandestinos de resíduos sólidos e extração ilegal de areia 9 . Na Lagoa do Guandu, ponto de encontro dos rios Guandu, Poços, Queimados, Cabuçu e Ipiranga, a situação piora, pois, além de as águas estarem bastante poluídas, há baixa taxa de renovação hídrica 4,9.

Em diagnóstico recente, foi verificado que o índice de coleta e tratamento de esgoto é muito baixo na bacia do Rio Guandu. Dos 15 municípios, apenas três possuem rede de coleta e tratamento de esgoto; ademais, mesmo nesses municípios, os índices de tratamento do esgoto gerado são insuficientes: Nova Iguaçu, 1,45\%; Piraí, 19,5\%; e Rio de Janeiro, 40\% 19.

Em levantamento realizado de agosto a dezembro de 2019 pelo Comitê da Bacia Hidrográfica do Rio Guandu, verificou-se que, das 78 estações de tratamento de esgoto existentes, 45 estavam com restrições ou paradas por problemas elétricos, mecânicos e, em alguns casos, por ausência de rede de coleta 21. Em Nova Iguaçu, onde está localizada a ETA Guandu, somente 13 estações de tratamento de esgoto estavam em operação. A consequência é o despejo de 10 milhões de litros de esgoto por dia no Rio Guandu e em seus afluentes 22 .

Além da presença de carga orgânica e de coliformes termotolerantes no esgoto doméstico, há outros poluentes considerados emergentes, como hormônios e cafeína 23,24 . Produtos químicos considerados poluentes emergentes podem acarretar distúrbios endócrinos, causar problemas congênitos, afetar a saúde reprodutiva 25 , bem como ocasionar tumores cancerígenos e induzir o desenvolvimento de resistência a patógenos bacterianos, incluindo resistência a múltiplas drogas 26,27.

As águas da bacia do Guandu são monitoradas tanto pela CEDAE quanto pelo órgão ambiental (Instituto Estadual do Ambiente - INEA), de forma a não comprometer a possibilidade de tratamento pela ETA Guandu 9,28. Apesar de o aporte de poluição que chega a esta estação de tratamento ser muito grande, ele é atenuado pela diluição decorrente da transposição do Paraíba do Sul, exceto em situação de escassez hídrica, pela priorização do atendimento às cidades a jusante deste rio 29 . Ainda assim, $\mathrm{o}$ fato é que a capacidade da bacia hidrográfica do Guandu para absorver a poluição e se reorganizar foi reduzida ao longo dos anos, e um resultado visível dessa degradação foi a contaminação da água com geosmina 29.

Em adição, a falta de investimento em saneamento e a ocupação desordenada da bacia do Rio Guandu aumentaram a incidência de doenças como hepatite A, verminoses, diarreias de diferentes etiologias e leptospirose, principalmente entre a população de baixa renda, que sofre pela contaminação da água potável, tanto na rede de abastecimento como em poços, em virtude da contaminação do lençol freático. Com efeito, em 2018, foi observado que em nenhum dos 15 municípios da bacia do Rio Guandu a portaria de qualidade da água foi atendida em sua totalidade ${ }^{30}$. No Brasil, as doenças de transmissão fecal-oral (diarreias, febres entéricas e hepatite A) foram responsáveis por $87 \%$ das internações causadas pelo saneamento inadequado no período de 2000 a 2013 31. A Organização 
Mundial da Saúde (OMS) aponta que o acesso a água potável e esgotamento sanitário adequado é de fundamental importância para a redução desses agravos 32 .

No início do mês de janeiro de 2020, coincidindo com a presença de geosmina na água distribuída pela CEDAE, a população do Rio de Janeiro apresentou aumento nos problemas de diarreia e náusea. A água apresentava sabor de terra, odor forte e, principalmente nas zonas Norte e Oeste, também cor amarronzada. Conforme declarações da CEDAE, esta substância não apresentava risco à saúde e poderia ser consumida, mas dados obtidos nas unidades de pronto atendimento (UPAs) de Santa Cruz e Campo Grande indicaram que, no período de 20 de dezembro de 2019 a 05 de janeiro de 2020, houve 783 casos de gastroenterite e vômitos, de origem infecciosa ou não, contra 282 no mesmo período de 2018 a 2019. Aumento significativo também ocorreu nos casos de diarreia, com 588 ocorrências contra 378 no período anterior 33 .

\section{Ações realizadas para despoluição das águas da bacia do Rio Guandu}

Mesmo antes de a CEDAE ser criada, já havia investimentos em abastecimento de água e esgotamento sanitário na Região Metropolitana do Rio de Janeiro, que sempre privilegiaram as áreas nobres da cidade (Centro e Zona Sul). Em estudo que analisou os investimentos aplicados desde 1975, ano da criação da CEDAE, até 1991, verificou-se que, na Baixada Fluminense, foi apenas iniciado, em 1986, um projeto-piloto 34 .

Em 2006, foi instituído pela primeira vez o Plano Estratégico de Recursos Hídricos do Comitê da Bacia Hidrográfica do Rio Guandu, com o suporte da ANA. Sua mais recente revisão data de 6 de dezembro de 2018 35. O PERH é orientado para planejamento de curto, médio e longo prazo (25 anos). O de curto prazo (quatro anos) prevê a elaboração de planos municipais de água, esgoto, resíduos sólidos e drenagem urbana, além de estudos e projetos para abastecimento de água e para esgotamento sanitário. Prevê investimentos da ordem de 2,27 bilhões de reais, sendo mais de $80 \%$ em saneamento 35 .

Além disso, o artigo 6 da Lei Estadual no 5.234/2008 36 estipula que 70\% dos valores arrecadados da cobrança das prestadoras de serviço de saneamento pelo uso dos recursos hídricos sejam aplicados na coleta e tratamento dos esgotos. Segundo o Comitê da Bacia Hidrográfica do Rio Guandu, já foram destinados mais de BRL 55 milhões aos municípios e à CEDAE para ações, planos e projetos em esgotamento sanitário. Já foram entregues projetos para oito municípios: Paracambi, Queimados, Nova Iguaçu, Barra do Piraí, Piraí, Seropédica, Itaguaí e Miguel Pereira, e estão em fase de elaboração os projetos para Mangaratiba, Rio Claro, Japeri, Vassouras, Engenheiro Paulo de Frontin e Mendes 37. Estão sendo, também, estudadas alternativas de saneamento mais adequadas, classificando as áreas em termos de criticidade de esgotamento sanitário para elaboração dos projetos executivos, cuja obra ficará a cargo das prefeituras. Este trabalho está em execução pelo Consórcio Profill/Tecnologia em Saneamento Ambiental Ltda., ao custo total de BRL 1.551.858,38, pagos com recursos provenientes da cobrança pelo uso da água, com previsão de finalização em fevereiro de 202137.

O que se observa é que, além de diagnósticos e projetos, na prática, tem sido lenta ou ausente a implantação das obras de rede de coleta e estações de tratamento de esgoto, além de persistirem os problemas nas estações existentes. Com base na urgência e complexidade do problema ambiental, propõe-se utilizar a metodologia de Integração Sistêmica como instrumento de mapeamento e convergência dos interesses dos diversos atores para a despoluição da bacia do Rio Guandu.

\section{Integração Sistêmica como instrumento para implementação do autocontrole}

Dada à multidisciplinaridade do problema, composto de fenômenos físicos, químicos, biológicos, sociais e culturais 38 , observa-se a necessidade da transposição das fronteiras para a possibilidade de cooperação plena ${ }^{39}$. Nesse sentido, uma estratégia de atuação é a Integração Sistêmica, metodologia que se baseia em três conceitos: sistema, rede e escala. O sistema é a estrutura, na qual as partes afetam todo o sistema e sua organização e variam em escala 40. Cada parte de um sistema se ordena em um sistema maior, que está em constante movimento e se reorganizando 41. A interação entre as partes 
do sistema é explicada pelo conceito de rede, na qual há formação de parcerias e espaços de negociação 39,42; cada parte é beneficiada pela ação integrada de todos os atores sociais.

O grande desafio da atuação ambiental está na escala de ação, pois se deve pensar globalmente e atuar localmente 43 . As ações devem ser orientadas para aquele espaço físico, onde haja fortalecimento da gestão ambiental mediante a criação de um nível primário ambiental, com o envolvimento da comunidade local na discussão sobre a melhoria de seu meio ambiente físico (natural e construído) 39,44.

Seguindo essa premissa, a proliferação de geosmina e a crise no abastecimento de água podem ser vistas pela Integração Sistêmica como importantes elementos para a convergência de interesses na solução do problema ambiental, uma vez que estejam identificadas as entidades cuja convergência de interesses alavancariam o processo da despoluição da bacia do Rio Guandu, bem como as entidades a serem empoderadas e articuladas para a concretização do projeto (Figura 3) 45.

\section{Figura 3}

Identificação da convergência de interesses e de sua concretização.

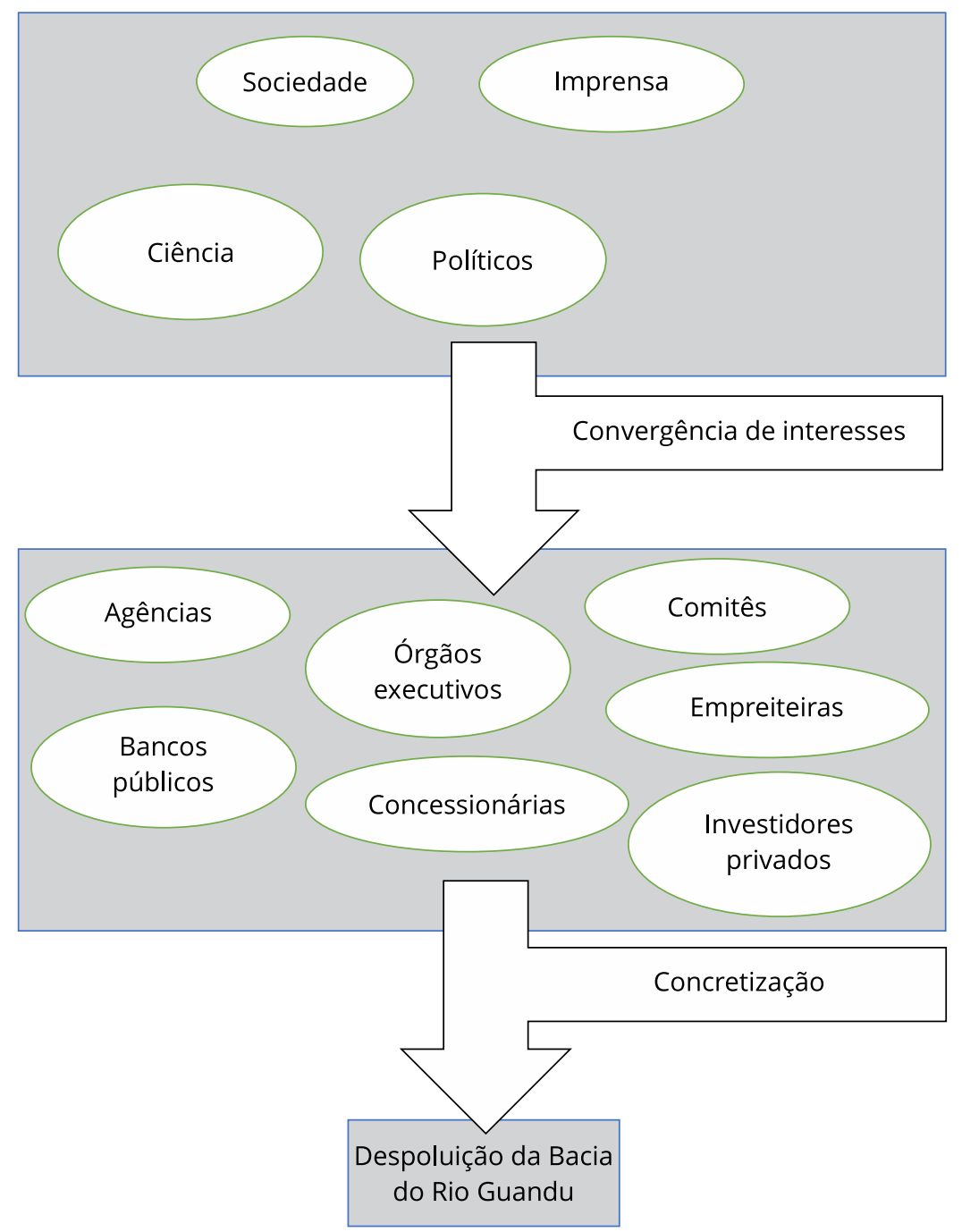

Fonte: elaboração própria. 
A utilização da metodologia de Integração Sistêmica permite identificar o papel de cada ator na mobilização social para o controle da poluição: a sociedade exige água de qualidade, a ciência identifica os problemas decorrentes das alterações de qualidade da água, apontando como solução a despoluição da bacia do Rio Guandu, e a imprensa repercute adequadamente o assunto para manter viva a mobilização, pressionando o poder público. Os políticos identificam uma tendência consensual da elite social e empresarial e das classes menos favorecidas pela urgência do saneamento dessa região, priorizando sua realização 11 .

Adicionalmente aos recursos públicos, pode-se incentivar a participação dos investidores privados, por meio de um equacionamento de concessões regionalizadas que garantam uma razoável taxa de retorno e propicie a redução do risco empresarial. Isso se obtém com a perspectiva da perenidade do equilíbrio econômico-financeiro dos contratos, decorrente da maturidade institucional das prefeituras na gestão das tarifas, com a segurança jurídica e ainda com o viés de equilíbrio fiscal das contas públicas.

Um conjunto adequado de leis, atribuições bem definidas entre agências, comitês, órgãos executivos e a concessionária, a competência das universidades na pesquisa e a expertise das empreiteiras na realização dos projetos garantiriam a adequada execução.

\section{Setores relacionados ao processo de despoluição do Rio Guandu}

De forma a avaliar o potencial de atuação de cada setor na despoluição da bacia do Rio Guandu, conforme já mencionado, optou-se por dividi-los em dois grupos. O primeiro grupo de setores tem como atuação predominante a mobilização para convergência de interesses, enquanto o segundo grupo tem a responsabilidade de efetivar a ação, devendo atuar de forma articulada. Como informação adicional, quando aplicável, são descritas as ações efetivadas por cada setor em relação à crise de abastecimento de água relacionada à presença da geosmina na água consumida pela população da Região Metropolitana do Rio de Janeiro.

\section{Grupo de mobilização}

\section{- Ciência}

Universidades e institutos de pesquisa cariocas participam ativamente da conscientização da sociedade. Em relação à contaminação da água, professores especialistas nas áreas de recursos hídricos, saneamento, saúde e outras áreas correlatas, como a Universidade Federal do Rio de Janeiro (UFRJ), Universidade do Estado do Rio de Janeiro (UERJ) e a Fundação Oswaldo Cruz (Fiocruz), realizaram vários estudos antes e após o que ocorreu, alertando para o risco do grande aporte de esgoto no Rio Guandu e ressaltando que a deterioração ambiental nos mananciais compromete a qualidade da água, atrapalha o tratamento e pode gerar risco à saúde pública 45,46. Além disso, a detecção da geosmina em alta concentração na água distribuída indicava a existência de grande quantidade de cianobactérias que liberam cianotoxinas, as quais precisam ser retiradas no processo de tratamento da água. Mesmo que não houvesse toxidez comprovada, os padrões de potabilidade da água eram considerados insuficientes por não atenderem a Portaria de Consolidação no 5, de 28 de setembro de 2017, do Ministério da Saúde 47. Essa portaria fixa níveis para amônia, ferro e sódio, percepção de gosto e odor. Essa percepção alterada poderia fazer com que a população recorresse a outras fontes de abastecimento de água menos seguras, com risco à sua saúde 48,49.

Em 2019, o ambientalista Mario Moscatelli, da UniverCidade, confirmou esse problema, citando análise realizada pelo INEA, que considerou as condições da água dos Rios dos Poços, Queimados e Ipiranga de "ruins" a "muito ruins" 50. 


\section{- Imprensa}

A imprensa, que atualmente se expressa por diversas mídias, é fundamental para explicitar a emergência do problema e criar um ambiente propício de respaldo às ações dos representantes da sociedade. No caso da contaminação da água, foi a imprensa que alertou a sociedade sobre a gravidade da situação.

\section{- Sociedade}

A Constituição Brasileira possui diversas frentes constituídas como representativas da sociedade. Em relação à contaminação da água, o Ministério Público do Estado do Rio de Janeiro (MPRJ), por meio do Grupo de Atuação Especializada em Meio Ambiente (GAEMA/MPRJ), realizou, no dia 13 de janeiro, vistoria no Rio Guandu, no trecho de Nova Iguaçu, para verificação das condições dos equipamentos e qualidade da ETA Guandu. Nessa visita, estavam presentes órgãos competentes e instituições parceiras, como a Fiocruz, a UFRJ e a UERJ, ocasião em que ocorreu a coleta de água para análise em diferentes pontos e fases do processo, da captação ao pós-tratamento, em busca de respostas para os recentes flagrantes e denúncias sobre as más condições da água 51.

Focada na melhora da produção de água do Guandu, a Organização Não-governamental (ONG) Conservação Internacional Brasil (CI-Brasil, https://www.conservation.org/brasil) já trabalhou em um projeto de restauração na bacia desse rio, realizando o plantio de milhões de árvores 52. Em 2018, a mesma ONG foi envolvida em outro projeto de reflorestamento, fruto de uma parceria com o braço ambiental do Rock in Rio, o Ministério do Meio Ambiente, o Fundo Global para o Meio Ambiente (GEF), o Fundo Brasileiro para a Biodiversidade (Funbio) e o Banco Mundial 53.

A sociedade, como fator mobilizador, reveste-se de maior importância pelo fato de os municípios deterem a titularidade dos serviços de saneamento. É essencial, portanto, que a população tenha a cultura sobre a importância do saneamento para a qualidade de sua vida e pressione suas prefeituras para priorizarem tanto a coleta como o tratamento de esgotos.

\section{- Políticos}

A orientação política, responsável pelo direcionamento das ações do governo, pelo acolhimento legislativo e pela alocação de recursos provenientes dos bancos públicos, é o ponto culminante de todo o processo de mobilização. Complementarmente, é por intermédio das câmaras de vereadores que há a aprovação, em audiências públicas, dos Planos Municipais de Saneamento Básico (PMSB), em que, além dos diagnósticos, são estabelecidas metas e indicadores visando à melhoria do serviço prestado. Foi estabelecido pelo Decreto no 10.203/2020 54 que os municípios devem elaborar até dezembro de 2022 seus PMSB para obterem investimentos do Governo Federal. Na bacia do Rio Guandu, dos 15 municípios, nove (60\%) já têm PMSB, cinco (33,3\%) estão com o plano em andamento e um município não informou 55. É a partir da orientação política que as ações são materializadas pelos setores do segundo grupo.

Em relação à crise no abastecimento de água, a Assembleia Legislativa do Estado do Rio de Janeiro enviou ofícios à CEDAE e à Secretaria de Estado de Ambiente e Sustentabilidade solicitando informações sobre as alterações na qualidade da água do Sistema Guandu e cobrando soluções para o problema 56 .

\section{Grupo de efetivação}

\section{- Órgãos executivos}

As prefeituras dos 15 municípios que compõem a bacia do Rio Guandu detêm a titularidade na prestação de serviços de saneamento. Mesmo concedendo-os à concessionária regional, são eles que definirão a entidade responsável por sua regulação e fiscalização (Lei no 11.445/2007 atualizada pela Lei no 14.026, de 15 de julho de 2020) 12,13. Os municípios da bacia do Rio Guandu deverão decidir se aderem ao projeto proposto pelo Banco Nacional de Desenvolvimento Econômico e Social (BNDES) 
de licitação da concessão dos serviços de saneamento de forma regionalizada 57 . Esse projeto prevê investimentos de BRL 11,9 bilhões (USD 2,6 bilhões) em água e BRL 20,7 bilhões (USD 4,6 bilhões) em esgoto 58 . Nota-se que, no que se refere à contaminação da água com geosmina no início de 2020, não há registro de qualquer ação tomada diretamente pelos executivos dos governos municipais.

O Governo do Estado do Rio de Janeiro tem, sob a sua estrutura, diferentes órgãos com atuação definida quanto ao saneamento; ademais, tem, atualmente, sob sua propriedade, a concessionária CEDAE. Como apoio ao Governo Estadual nas ações ambientais, há o Fundo Estadual de Conservação Ambiental e Desenvolvimento Urbano (FECAM) e o INEA. O FECAM foi criado pela Lei Estadual no 1.060, de 10 de novembro de 198659 e tem como finalidade destinar 5\% dos royalties de extração de petróleo e multas aplicadas por órgãos ambientais a projetos e programas ambientais e de desenvolvimento urbano. O INEA 60 executa as políticas estaduais de meio ambiente, recursos hídricos e recursos florestais, além de gerenciar o Fundo Estadual de Recursos Hídricos (FUNDRHI), que, por sua vez, faz parte do Sistema Estadual de Gerenciamento de Recursos Hídricos (SEGRHI), cuja função é viabilizar economicamente atividades e promover a descentralização de sua gestão 60 .

O Governo Federal atua em diferentes frentes na bacia do Rio Guandu. A ANA é responsável pela Política Nacional de Recursos Hídricos e, após a promulgação do novo marco legal do saneamento, em 15 de julho de 2020, é também responsável pela supervisão regulatória dos serviços de saneamento básico (Lei no 14.026/2020) 13. O Ministério da Saúde atua através do Programa Nacional de Vigilância da Qualidade da Água para Consumo Humano (VIGIÁGUA), que realiza, junto às Secretarias Estaduais e Municipais da Saúde, não só ações de monitoramento da qualidade da água consumida (análise de parâmetros físico-químicos e microbiológicos) 61,62,63 como também inspeções em sistemas de abastecimento, verificando se a água consumida está dentro dos padrões de potabilidade.

\section{- Agência}

A Agência Reguladora de Energia e Saneamento Básico do Estado do Rio de Janeiro (AGENERSA) 64 é responsável pela regulação e fiscalização dos serviços de abastecimento de água e esgotamento sanitário operados pela CEDAE quanto à manutenção dos serviços adequados, com eficiência, tarifas razoáveis, equilíbrio econômico-financeiro e cumprimento das metas de ampliação de cobertura nas áreas em que a concessionária está presente. Além da Lei Estadual no 4.556/2005 64 e da Lei Federal no 11.445/2007 12, os trâmites para a AGENERSA regular a CEDAE são determinados pelo Decreto Estadual no 45.344, de 17 de agosto de 201565.

No caso da contaminação por geosmina, a AGENERSA multou a CEDAE por não divulgar relatórios sobre a concentração dessa substância e determinou que a companhia buscasse soluções para o tratamento de água, arcando com os custos relacionados às aquisições de equipamentos e do carvão ativado, não permitindo que a concessionária embutisse esse custo na tarifa para seu reequilíbrio econômico-financeiro. Também determinou que a CEDAE comunique imediatamente à população sempre que houver deterioração na qualidade da água fornecida (AGENERSA. http://www.agenersa. rj.gov.br, acessado em 02/Abr/2020).

\section{- Concessionária}

A CEDAE é uma concessionária de serviço público e pessoa jurídica de direito privado, inaugurada em 1975, como sucessora da CEDAG e da ESAG, empresas do antigo Estado da Guanabara, que atuavam separadamente para água e para esgotamento sanitário. A CEDAE tem como escopo captar, tratar, realizar adução e distribuição de águas, bem como coletar, transportar, tratar e realizar a destinação final dos esgotos gerados dos municípios conveniados do Estado do Rio de Janeiro, incluindo a execução das obras para tais finalidades (CEDAE. https://www.cedae.com.br, acessado em 31/ Mar/2020). Com a crescente poluição do Rio Guandu, há o aumento da concentração de poluentes, o que encarece muito o tratamento de água e pode até torná-lo inviável 9. 


\section{- Comitê}

O Comitê da Bacia Hidrográfica do Rio Guandu foi criado pelo Decreto Estadual no 31.178, de 3 de abril de 2002 66, substituído pelo Decreto Estadual no 45.463. É um órgão colegiado (integrado por órgãos do governo, universidades, prefeituras, concessionárias e usuários), vinculado ao Conselho Estadual de Recursos Hídricos (CERHI), com atribuições consultivas, normativas e deliberativas, de nível regional. Integra o SEGRHI e visa a promover a gestão descentralizada e participativa dos recursos hídricos na bacia hidrográfica. Para isso, realiza estudos, programas de educação ambiental e de mobilização social, além de projetos que visam à melhoria da quantidade e qualidade das águas dessa bacia 11. Atua em 15 municípios que, juntos, compreendem uma área total de $3.600 \mathrm{~km}^{2}$, onde se localizam as bacias hidrográficas que drenam para a Baía de Sepetiba. Dentre esses, os municípios de Engenheiro Paulo de Frontin, Itaguaí, Japeri, Mangaratiba, Paracambi, Queimados e Seropédica estão totalmente inseridos na bacia do Guandu, enquanto Barra do Piraí, Mendes, Miguel Pereira, Nova Iguaçu, Piraí, Rio Claro, Rio de Janeiro e Vassouras estão parcialmente inseridos (Comitê da Bacia Hidrográfica do Rio Guandu. Legislação. http://www.comiteguandu.org.br/legislacao.php, acessado em 25/Mar/2020).

Após a instituição da Lei Estadual no 4.247/2003 67, o Comitê da Bacia Hidrográfica do Rio Guandu estabeleceu critérios para a cobrança pelo uso da água visando à obtenção de recursos financeiros para financiamento de programas e intervenções contemplados pelo Plano de Bacia (instrumento de planejamento que orienta as ações que devem ser tomadas visando a recuperação, proteção e conservação da bacia hidrográfica). Em 2005, iniciou-se a cobrança e, em 2015, o valor do preço público unitário foi alterado de BRL 0,02/ $\mathrm{m}^{3}$ para BRL 0,04/m33, cobrado a partir de janeiro de 2017. Com essa cobrança, a arrecadação líquida até 2019 acumulou BRL 187.844.264,28 68.

Em relação à contaminação da água pela geosmina, o Comitê da Bacia Hidrográfica do Rio Guandu visitou a ETA Guandu para acompanhar a fiscalização e a coleta de amostras no processo de tratamento de água 69.

\section{- Investidores privados}

Sabe-se que o ambiente propício para atrair o investimento privado inclui uma razoável taxa de retorno e a redução do risco empresarial. O novo marco do saneamento visa a trazer a segurança jurídica, enquanto a perspectiva de que sejam reduzidas amplamente as despesas futuras com saúde pública, caso sejam efetivadas as obras de universalização do saneamento, tem o viés de equilíbrio fiscal. Com a regionalização das concessões, pode ser equacionada uma boa taxa de retorno, através, inclusive, da perspectiva de licitação da concessão de prestação de serviços de saneamento 70 . Além disso, considerando que, pelo escopo de concessão à iniciativa privada apresentado pelo BNDES, o tratamento da água permanecerá com a CEDAE e a tarifa de água para o consumidor final não deverá ser majorada, uma boa taxa de retorno para o investidor privado será função principalmente do valor que a CEDAE cobrará pela água tratada, uma vez que, conforme acordos firmados, a tarifa de compra será de USD $1,70 / \mathrm{m}^{3} 71$.

\section{Caminhos para a convergência de interesses em prol da gestão de esgotamento sanitário da bacia do Rio Guandu}

É fundamental obter a convergência de interesses para a efetivação da coleta e tratamento de esgotos para a densa população predominantemente pobre da bacia do Rio Guandu, que há décadas tem sido mal atendida. Considerando que a conscientização quanto ao bem comum e à preservação do meio ambiente ainda é incipiente, o caminho para a convergência de interesses passa por evidenciar que uma das consequências da falta de saneamento para populações de baixa renda é a alteração na qualidade da água da população como um todo. Dessa forma, esse tema pode ser alçado a um patamar efetivamente prioritário.

A crise no abastecimento de água no Rio de Janeiro expôs o descaso com a coleta e o tratamento de esgoto nas áreas densamente povoadas pela população de baixa renda. Uma vez que a vida da popula- 


\section{Figura 4}

Histórico de arrecadação na bacia do Rio Guandu.

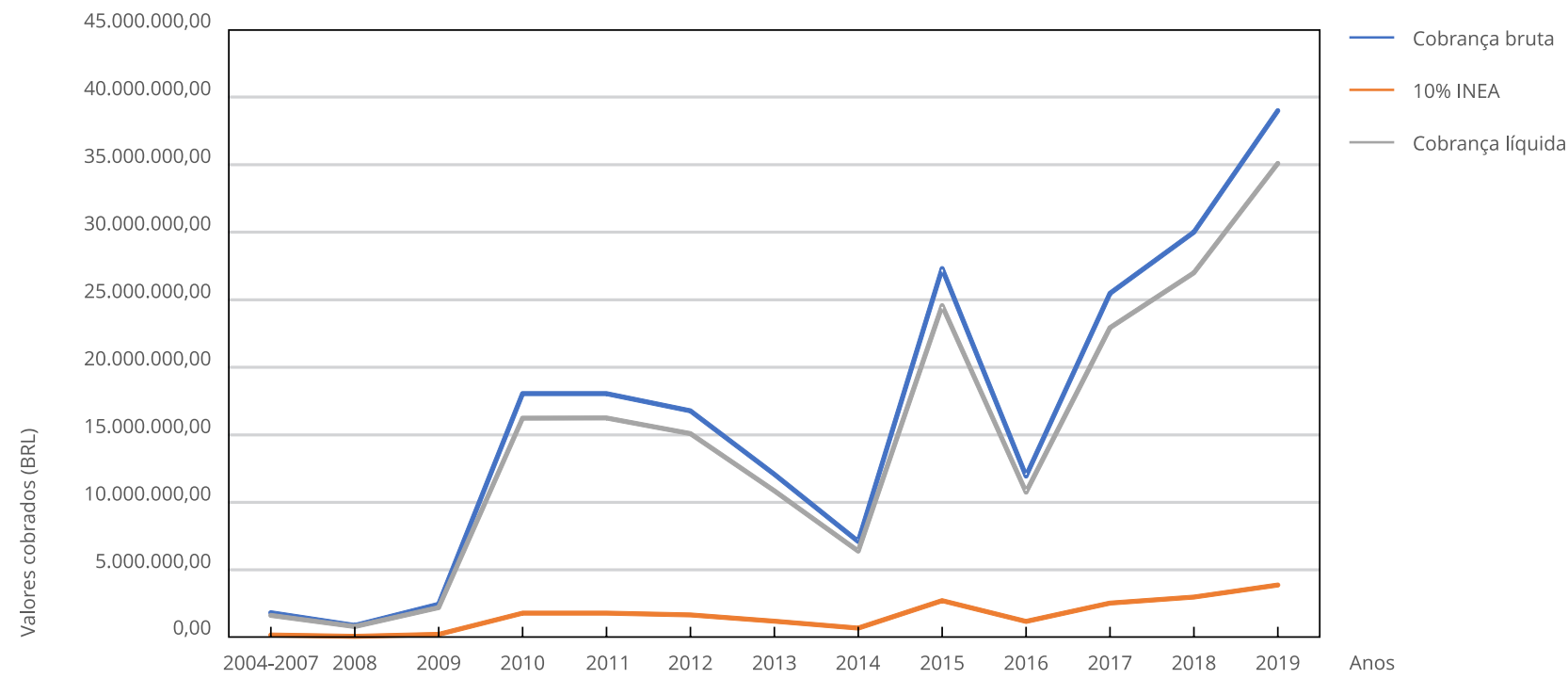

INEA: Instituto Estadual do Ambiente. 
Foram destinados ao saneamento, de janeiro a setembro de 2019, cerca de BRL 18 milhões provenientes da cobrança pelo recurso hídrico. No entanto, o BNDES estima que seria necessário investimento total de BRL 33,5 bilhões em saneamento para se obter 90\% de cobertura. A partir deste montante, o Comitê da Bacia Hidrográfica do Rio Guandu projetou um investimento anual de BRL 1,4 bilhão até 2042, porém, só em Nova Iguaçu e em Queimados, seria necessário investir anualmente BRL 776 milhões. Atualmente, dos investimentos necessários, conforme detalhado no item 5, apenas uma pequena parte já tem estudos realizados, necessários para a licitação 37 .

\section{Conclusão}

Este artigo analisa a crise de abastecimento de água na Região Metropolitana do Rio de Janeiro ocorrida em 2020, causada pela excessiva carga poluente no manancial da ETA do Guandu. Chegou-se à conclusão de que esta pode ser a grande oportunidade de se obter a convergência de interesses necessária para viabilizar o investimento em infraestrutura de esgotamento sanitário na bacia do Rio Guandu. Historicamente essa área sempre foi tratada com descaso por ser predominantemente habitada por população de baixa renda.

A metodologia utilizada, de Integração Sistêmica, possibilitou que fossem identificados dois grupos setoriais: um grupo que tem o potencial de mobilizar e convergir os interesses para viabilizar a realização das obras e um grupo que deve atuar de forma articulada para sua concretização.

Para que se consiga capturar o interesse de toda a sociedade e do empresariado, é necessário fortalecer cognitivamente a associação entre a degradação ambiental da bacia do Rio Guandu e a ameaça constante de queda da qualidade da água consumida. Essa associação seria proporcionada pela comunidade científica e pela mídia. Sendo essa premissa atendida, é bem provável que tais ações despertem a vontade política, porquanto, com a despoluição da bacia do Rio Guandu, estaria sendo angariado capital político pelo atendimento aos desejos da sociedade como um todo. Investidores privados poderão ser atraídos por um bom equacionamento regional das concessões, que lhes confiram uma razoável taxa de retorno, segurança jurídica e menor risco pelo viés de equilíbrio fiscal, apontado pela queda futura nas despesas com a saúde pública decorrente da drástica redução de doenças de veiculação hídrica.

Os benefícios seriam imensos, já que a despoluição do Rio Guandu traria ganho social e econômico à região, com aumento de qualidade de vida, diminuição de doenças, aumento de produtividade, em um novo patamar de conscientização em relação ao bem comum, à água e à preservação do meio ambiente. Este estudo pode servir de alerta, com o objetivo de contribuir para a melhoria da segurança do abastecimento, a fim de que crises como a que ocorreu em janeiro de 2020 não se repitam no Estado do Rio de Janeiro. 


\section{Colaboradores}

Todas as autoras contribuíram em todas as etapas da produção do artigo.

\section{Informações adicionais}

ORCID: Debora Cynamon Kligerman (0000-00027455-7931); Sandra Novellino Sancanari (00000002-9208-375X); Joseli Maria Rocha Nogueira (0000-0003-4923-6500).

\section{Referências}

1. Campos AC.MPRJ faz vistoria e coleta amostra de água na Estação Guandu da Cedae. Agência Brasil 2020; 14 jan. https://agenciabrasil.ebc. com.br/geral/noticia/2020-01/mprj-faz-vis toria-e-coleta-amostra-de-agua-na-estacaoguandu-da-cedae.

2. Juliana M, Smiderle I, Capodeferro T. Crise na Cedae: como chegou até aqui? Revista Conjuntura Econômica 2020; 74:34-7.

3. Conselho Regional de Química. Análise da Câmara Técnica de Meio Ambiente acerca da crise hídrica fluminense. http://ct.crq3.org. $\mathrm{br} / \mathrm{wp}$-content/uploads/2020/01/Nota-criseh\%C3\%ADdrica-CTMA.pdf (acessado em 16/ Mai/2020).

4. Companhia Estadual de Águas e Esgoto do Rio de Janeiro. Estudo de impacto ambiental - EIA/Relatório de Impacto Ambiental, Relatório Final dezembro de 2009. http://www. ceivap.org.br/downloads2011/CEDAE_EIA. pdf (acessado em 27/Mar/2020).

5. Fundação Nacional de Saúde. Manual de controle da qualidade da água para técnicos que trabalham em ETAS. Brasília: Fundação Nacional de Saúde. Brasília: Fundação Nacional de Saúde; 2014.

6. Companhia Estadual de Águas e Esgoto do Rio de Janeiro. Relatório de Impacto Ambiental RIMA das obras de proteção da tomada d'água da CEDAE no Rio Guandu. http://www.ceivap.org.br/downloads2011/CEDAE_RIMA. pdf (acessado em 27/Mar/2020).

7. Mello I. Cedae engaveta há 10 anos obra que evitaria crise do Rio de Janeiro. UOL Notícias 2020; 19 jan. https://noticias.uol.com.br/ cotidiano/ultimas-noticias/2020/01/19/ce dae-engaveta-por-10-anos-obra-que-evitariacontaminacao-de-agua-no-rio.htm.

8. Leoneti AB, Prado EL, Oliveira SVWB. Saneamento básico no Brasil: considerações sobre investimentos e sustentabilidade para o século XXI. Revista de Administração Pública 2011; 45:331-48.

9. Salamene S. Estratificação e caracterização ambiental da área de preservação permanente do Rio Guandu/RJ, 2007. Revista Árvore 2011; 35:221-31.

10. Brasil. Lei Federal no 9.984, 17 de julho de 2000. Dispõe sobre a criação da Agência Nacional de Águas e Saneamento Básico (ANA), entidade federal de implementação da Política Nacional de Recursos Hídricos, integrante do Sistema Nacional de Gerenciamento de Recursos Hídricos (Singreh) e responsável pela instituição de normas de referência para a regulação dos serviços públicos de saneamento básico. Diário Oficial da União 200; 18 jul.

11. Tubbs Filho D, Antunes JCO, Vettorazzi JS. Bacia Hidrográfica dos Rios Guandu, da Guarda e Guandu-Mirim - experiências para gestão dos recursos hídricos. Rio de Janeiro: Instituto Estadual do Ambiente; 2012. 
12. Brasil. Lei Federal no $11.445,5$ de janeiro de 2007. Estabelece as diretrizes nacionais para o saneamento básico; cria o Comitê Interministerial de Saneamento Básico; altera as Leis no 6.766, de 19 de dezembro de 1979, 8.666, de 21 de junho de 1993, e 8.987, de 13 de fevereiro de 1995; e revoga a Lei no 6.528, de 11 de maio de 1978. Diário Oficial da União 2007; 8 jan.

13. Brasil. Lei Federal no 14.026, 15 de julho de 2020. Atualiza o marco legal do saneamento básico e altera a Lei no 9.984, de 17 de julho de 2000, para atribuir à Agência Nacional de Águas e Saneamento Básico (ANA) competência para editar normas de referência sobre o serviço de saneamento, a Lei no 10.768 , de 19 de novembro de 2003, para alterar o nome e as atribuições do cargo de Especialista em Recursos Hídricos, a Lei no 11.107, de 6 de abril de 2005, para vedar a prestação por contrato de programa dos serviços públicos de que trata o art. 175 da Constituição Federal, a Lei no 11.445 , de 5 de janeiro de 2007, para aprimorar as condições estruturais do saneamento básico no País, a Lei no 12.305 , de 2 de agosto de 2010, para tratar dos prazos para a disposição final ambientalmente adequada dos rejeitos, a Lei no 13.089 , de 12 de janeiro de 2015 (Estatuto da Metrópole), para estender seu âmbito de aplicação às microrregiões, e a Lei no 13.529, de 4 de dezembro de 2017, para autorizar a União a participar de fundo com a finalidade exclusiva de financiar serviços técnicos especializados. Diário Oficial da União 2020; 16 jul.

14. Assembleia Legislativa do Rio de Janeiro. Projeto de Lei no 385, 04 de junho de 2003. Ementa: que dispõe sobre a Política Estadual de Saneamento, seus Instrumentos e dá outras providências. http://alerjln1.alerj.rj.gov. br/scpro0307.nsf/e00a7c3c8652b69a83256cca00646ee5/dd0c235a 8cb5edb283256d21 0068b032?OpenDocument (acessado em 25/ Set/2020)

15. Governo do Estado do Rio de Janeiro. Lei Estadual no 3.239, 2 de agosto de 1999. Institui a política estadual de recursos hídricos; cria o sistema estadual de gerenciamento de recursos hídricos; regulamenta a constituição estadual, em seu artigo 261, parágrafo 1o, inciso vii; e dá outras providências. Diário Oficial do Estado do Rio de Janeiro 1999; 3 ago.

16. Assembleia Legislativa do Rio de Janeiro. Lei Estadual no 4.247, 16 de dezembro de 2003. Dispõe sobre a cobrança pela utilização dos recursos hídricos de domínio do Estado do Rio de Janeiro e dá outras providências. 2003; Diário Oficial do Estado Rio de Janeiro 2003; 17 dez.

17. Assembleia Legislativa do Rio de Janeiro. Lei Estadual no 4.051, 30 de dezembro de 2002. Dispõe sobre a criação do Programa S.O.S Rio Paraíba do Sul, objetivando a sua revitalização, no Estado do Rio de Janeiro. Diário Oficial do Estado do Rio de Janeiro 2002; 31 dez.
18. Assembléia Legislativa do Estado do Rio de Janeiro. Lei Estadual no 4.191, 30 de setembro de 2003. Dispõe sobre a política estadual de resíduos sólidos e dá outras providências. Diário Oficial do Estado do Rio de Janeiro 2003; 2 out.

19. Secretaria Nacional de Saneamento, Ministério do Desenvolvimento Regional. $24^{\circ}$ diagnóstico dos serviços de água e esgotos, 2018. http://www.snis.gov.br/downloads/diagnosti cos/ae/2018/Diagnostico_AE2018.pdf (acessado em 03/Out/2020).

20. Companhia Estadual de Águas e Esgotos do Rio de Janeiro. Serviços de revisão do plano diretor de abastecimento de água da região metropolitana do Rio de Janeiro, relativamente aos municípios atendidos pelos sistemas Guandu, Ribeirão das Lajes e Acari - RJ. Rio de Janeiro: Companhia Estadual de Águas e Esgotos do Rio de Janeiro; 2004.

21. Comitê da Bacia Hidrográfica do Rio Guandu. Fórum de secretários de meio ambiente debate IMCS Verde e soluções para saneamento. https://www.comiteguandu.org.br/noticias. php?id=689 (acessado em 03/Out/2020).

22. Coelho H. Mais da metade das estações de tratamento de esgoto na bacia do Rio Guandu está com problemas ou sem funcionar. G1 2020; 22 jan. https://g1.globo.com/rj/rio-de-janei ro/noticia/2020/01/22/56percent-das-esta coes-de-tratamento-de-esgoto-na-bacia-dorio-guandu-estao-com-problemas-ou-semfuncionar.ghtml.

23. Fernandes JG. Ocorrência de poluentes emergentes nos Rios Piraí, Paraíba do Sul, Guandu e na água de abastecimento da Região Metropolitana do Rio de Janeiro [Tese de Doutorado]. Lorena: Escola de Engenharia de Lorena, Universidade de São Paulo; 2018.

24. Gonçalves ES. Ocorrência e distribuição de fármacos, cafeína e bisfenol-A em alguns corpos hídricos no estado do Rio de Janeiro [Tese de Doutorado]. Niterói: Universidade Federal Fluminense; 2012.

25. Poongothai S, Ravikrishnan R, Murthy P. Endocrine disruption and perspective human health implications: a review. Int J Toxicol 2007; 4:1-12.

26. Muñoz I, Gómez-Ramos MJ, Agüera A, Fernández-Alba AR, García-Reyes JF, MolinaDíaz A. Chemical evaluation of contaminants in wastewater effluents and the environmental risk of reusing effluents in agriculture. Trends Anal Chem 2009; 28:676-94.

27. UN Water. World Water Development. UNWater Annual Report 2017. https://www. unwater.org/publications/un-water-annualreport-2017/ (acessado em 18/Mai/2020).

28. Serber JB. Diagnóstico ambiental das atividades do Pólo Industrial de Queimados como subsídio ao Termo de Ajustamento de Conduta na gestão sustentável da Bacia Hidrográfica do Rio Guandu, RJ [Dissertação de Mestrado]. Rio de Janeiro: Universidade do Estado do Rio de Janeiro; 2005. 
29. Assembleia Legislativa do Estado do Rio de Janeiro. Campanha publicitária de conscientização sobre recursos hídricos do Rio Paraíba do Sul que abastecem o Rio Guandu. http:// alerjln1.alerj.rj.gov.br/scpro0711.nsf/02ac 6f279b568e24832566ec0018d839/2002a0ff 09f09a388325771a006a797b?OpenDocument (acessado em 14/Abr/2020).

30. Secretaria Nacional de Saneamento, Ministério do Desenvolvimento Regional. Sistema Nacional de Informações sobre Saneamento: informações e indicadores municipais consolidados - 2018. Brasília: Ministério do Desenvolvimento Regional; 2020.

31. Instituto Trata Brasil. Estudos ITB: conheça algumas doenças causadas pela falta de saneamento básico. http://www.tratabrasil.org. $\mathrm{br} / \mathrm{blog} / 2018 / 02 / 27 /$ doencas-falta-de-sanea mento-basico/ (acessado em 20/Abr/2020).

32. World Health Organization; United Nations Children's Fund. Progress on sanitation and drinking-water. 2013 update: Joint Monitoring Programme for Water Supply and Sanitation; Geneva: World Health Organization; 2013.

33. Goulart G. Água sob suspeita: Casos de diarreia, gastroenterite e vômito mais que dobram em UPAS da Zona Oeste. O Globo 2020; 8 jan. https://oglobo.globo.com/rio/agua-sob-sus peita-casos-de-diarreia-gastroenterite-vomi to-mais-que-dobram-em-upas-da-zona-oes te-1-24176922.

34. Marques EC. Equipamentos de saneamento e desigualdades no espaço metropolitano do Rio de Janeiro. Cad Saúde Pública 1996; 12:18193.

35. Comitê da Bacia Hidrográfica do Rio Guandu. Rumo à sustentabilidade hídrica. Revista Águas do Guandu 2019; (1):5-7.

36. Assembleia Legislativa do Estado do Rio de Janeiro. Lei Estadual no 5.234, 5 de maio de 2008. Altera a lei no 4.247, de 16 de dezembro de 2003, que dispõe sobre a cobrança pela utilização dos recursos hídricos de domínio do Estado do Rio de Janeiro e dá outras providências. Diário Oficial do Estado do Rio de Janeiro 2008; 6 mai.

37. Comitê da Bacia Hidrográfica do Rio Guandu. O desafio do saneamento. Revista Águas do Guandu 2019; (1):34-6.

38. Capra F. O ponto de mutação. 15ạ Ed. São Paulo: Cultrix; 1993.

39. Kligerman DC. Gestão ambiental integrada: recursos hídricos, saneamento e saúde [Tese de Doutorado]. Rio de Janeiro: Universidade Federal do Rio de Janeiro; 2001.

40. Kligerman DC, La Rovere EL, Costa MA. Management challenges on small-scale gold mining activities in Brazil. Environ Res 2001; 87:181-98.

41. Boff L. O despertar da águia: o dia-bólico e o sim-bólico na construção da realidade. 10a Ed. Petrópolis: Editora Vozes; 1998.
42. Dupuy G. Villes, systèmes et réseaux: le rôle historique des techniques urbaines. Réseaux 1984; 2:3-23.

43. Coronado Ramirez J. ¿Que és la globalizacion? Falacias del globalismo, respuestas a la globalización. Frontera Norte 2001; 13:155-63.

44. Marchant PE, Candia RC. Atenção primária ambiental - uma estratégia de sustentabilidade local. Santiago de Chile: Instituto de Ecología Política; 1996.

45. Campos AC. Problema da água no Rio requer soluções de longo prazo. Agência Brasil 2020; 31 jan. https://agenciabrasil.ebc.com.br/geral/ noticia/2020-01/problema-da-agua-no-rio -requer-solucoes-de-longo-prazo.

46. Conselho Deliberativo da Fiocruz divulga nota sobre a qualidade da água no Rio de Janeiro. Portal Fiocruz 2020; 10 fev. https://portal.fio cruz.br/noticia/conselho-deliberativo-da-fio cruz-divulga-nota-sobre-qualidade-da-aguano-rio-de-janeiro.

47. Ministério da Saúde. Portaria de Consolidação no 5 de 28 de setembro de 2017. Consolidação das normas sobre as ações e os serviços de saúde do Sistema Único de Saúde. Diário Oficial da União 2017; 3 out.

48. Universidade Federal do Rio de Janeiro. Nota Técnica sobre os problemas da qualidade da água que a população do Rio de Janeiro está vivenciando. https://ufrj.br/sites/default/fi les/img-noticia/2020/01/nota_tecnica_-_ca so_cedae.pdf (acessado em 28/Mar/2020).

49. Benedito SR. Crise da qualidade da água no Rio de Janeiro: contexto e disputas. Aliança pela alimentação adequada e saudável. https:// alimentacaosaudavel.org.br/crise-da-qualida de-da-agua-no-rio-de-janeiro-contexto-e-dis putas/6211/ (acessado em 30/Mar/2020).

50. Guimarães SP. Mario Moscatelli: biólogo denuncia a poluição de 20 anos. Veja Rio 2020; 6 mar. https://vejario.abril.com.br/cidade/ma rio-moscatelli-denuncia-poluicao-20-anos/.

51. Ministério Público do Estado do Rio de Janeiro. CEDAE Medida Judicial: qualidade da água distribuída no Estado. Notícias 2020; 17 jan. http://www.mprj.mp.br/home/-/detalhe-no ticia/visualizar/81307.

52. Granda A. Parceria para reflorestar margens do Guandu é anunciada no Rio. Agência Brasil 2015; 2 set. https://agenciabrasil.ebc.com.br/ geral/noticia/2015-09/parceria-para-reflores tar-margens-do-guandu-e-anuciada-no-rio.

53. Global Tree. Rock in Rio arrecada fundos para reflorestar as margens do Guandu. https:// www.globaltree.com.br/blog/rock-in-rio-ar recada-fundos-para-reflorestar-as-margensdo-guanduleilao-virtual-de-guitarras-auto grafadas-por-renomados-artistas-vai-arre cadar-uma-quantia-suficiente-para-o-plan tio-de-mais-de-nove-milhoes-de-arvoresna-bacia-do-rio-guandu (acessado em 29/ Mar/2020). 
54. Brasil. Decreto no 10.203 , de 22 de janeiro de 2020. Altera o Decreto no 7.217, de 21 de junho de 2010, que regulamenta a Lei no 11.445 , de 5 de janeiro de 2007, que estabelece diretrizes nacionais para o saneamento básico. Diário Oficial da União 2020; 23 jan.

55. Arêas VT. Estudo dos planos municipais de saneamento básico do Rio de Janeiro: a inserção dos assentamentos precários [Dissertação de Mestrado]. Rio de Janeiro: Escola Nacional de Saúde Pública Sergio Arouca, Fundação Oswaldo Cruz; 2019.

56. Natario G. Água: Alerj cobra informações da Cedae e governo. Publicações: Notícias 2020; 24 jan. http://www.alerj.rj.gov.br/Visualizar/ Noticia/48090?AspxAutoDetectCookieSu pport $=1$ (acessado em 30/Nov/2020).

57. Aroeira C. Projeto concessões regionalizadas do abastecimento de água e esgotamento sanitário do Estado do Rio de Janeiro. https:// acrj.org.br/wp-content/uploads/2020/07/ BNDES_ACRJ_Apresenta\% C 3\% A $7 \%$ C3\%A3o-SaneamentoRJ_20200730.pdf (acessado em 28/Nov/2020).

58. Gandra A. Maior obra do estado do Rio virá com privatização da CEDAE. Agência Brasil 2020; 12 fev. https://agenciabrasil.ebc.com. br/geral/noticia/2020-02/maior-obra-do-es tado-do-rio-vira-com-privatizacao-da-cedaediz-witzel (acessado em 28/Fev/2020).

59. Governo do Estado do Rio de Janeiro. Lei Estadual no 1.060, de 10 de novembro de 1986. Institui o Fundo Especial de Controle Ambiental - FECAM e dá outras providências. Diário Oficial do Estado do Rio de Janeiro 1986; 17 nov.

60. Governo do Estado do Rio de Janeiro. Lei no 5.101 de 04 de outubro de 2007. Dispõe sobre a criação do Instituto Estadual Do Ambiente INEA e sobre outras providências para maior eficiência na execução das políticas estaduais de meio ambiente, de recursos hídricos e florestais. Diário Oficial do Estado do Rio de Janeiro 2007; 7 out.

61. Ministério da Saúde. Portaria Ministerial no 1.565, 26 de agosto de 1994. Diário Oficial da União 1994; 26 ago.

62. Brasil. Lei Federal no 8.080, 19 de setembro de 1990. Dispõe sobre as condições para a promoção, proteção e recuperação da saúde, a organização e o funcionamento dos serviços correspondentes e dá outras providências. Diário Oficial da União 1990; 20 set.

63. Brasil. Lei Federal no 9.782, 26 de janeiro de 1999. Define o Sistema Nacional de Vigilância Sanitária, cria a Agência Nacional de Vigilância Sanitária, e dá outras providências. Diário Oficial da União 1999; 27 jan.

64. Governo do Estado do Rio de Janeiro. Lei Estadual no 4.556, de 6 de junho de 2005. Cria, estrutura, dispõe sobre o funcionamento da Agência Reguladora de Energia e Saneamento Básico do Estado do Rio de Janeiro - AGERERSA, e dá outras providências. Diário Oficial do Estado do Rio de Janeiro 2005. 7 jun.
65. Governo do Estado do Rio de Janeiro. Decreto Estadual no 45.344, de 17 de agosto de 2015. Estabelece as condições gerais para a regulação e fiscalização das atividades da Companhia Estadual De Águas E Esgotos - CEDAE - pela Agência Reguladora de Energia e Saneamento Básico do Estado do Rio De Janeiro - AGENERSA - e dá outras providências. Diário Oficial do Estado do Rio de Janeiro 2015; 18 ago.

66. Governo do Estado do Rio de Janeiro. Decreto Estadual no 31.178, de 3 de abril de 2002. Cria o Comitê da Bacia Hidrográfica do Guandu que compreende a Bacia Hidrográfica do Rio Guandu, incluídas as nascentes do Ribeirão das Lages, as águas desviadas do Paraíba do Sul e do Piraí, os afluentes ao Ribeirão das Lages, ao Rio Guandu e ao canal de São Francisco, até a sua desembocaduara na Baía de Sepetiba, bem como as Bacias Hidrográficas do Rio da Guarda e Guandu-Mirim. Diário Oficial do Estado do Rio de Janeiro 2002; 4 abr.

67. Governo do Estado do Rio de Janeiro. Lei Estadual no 4.247, 16 de dezembro de 2003. Dispõe sobre a cobrança pela utilização dos recursos hídricos de domínio do Estado do Rio de Janeiro e dá outras providências. Diário Oficial do Estado do Rio de Janeiro 2003; 17 dez.

68. Agência da Bacia do Rio Paraíba do Sul. Análise crítica da cobrança - contrato de gestão INEA no 03/2010. Regiões Hidrográficas Baía da Ilha Grande e Guandu. Resende: Agência da Bacia do Rio Paraíba do Sul; 2019.

69. CBH Rio das Velhas. Crise da água no rio Guandu denuncia a má qualidade do Rio e compromete o tratamento das águas. https:// cbhvelhas.org.br/noticias/crise-da-agua-norio-guandu-denuncia-a-ma-qualidade-do-rioe-compromete-o-tratamento-das-aguas/ (acessado em 27/Mar/2020).

70. Agência Nacional de Águas e Saneamento Básico. Novo marco do saneamento entra em vigor e deve trazer avanços econômicos, na saúde e no meio ambiente em todo o país. https://www.ana.gov.br/noticias/novo-mar co-do-saneamento-entra-em-vigor-e-devetrazer-avancos-economicos-na-saude-e-nomeio-ambiente-em-todo-o-pais (acessado em 04/Ago/2020).

71. Cavalcanti G. BNDES e governo do Rio chegam a acordo sobre tarifa da CEDAE. O Globo 2020; 4 dez. https://oglobo.globo.com/econo $\mathrm{mia} /$ governo-do-rio-bndes-chegam-acordosobre-preco-da-tarifa-de-agua-da-nova-cedae -edital-sai-dia-18-diz-banco-24781113.

72. Marjoriê C. Problemas com água da Cedae já atinge 86 bairros do Rio e seis cidades da Baixada. O Globo 2020; 14 jan. https://oglobo.globo.com/rio/problema-com-agua-da-ce dae-ja-atinge-86-bairros-do-rio-seis-cidadesda-baixada-confira-mapa-2-24188842. 


\section{Abstract}

In January 2020, the population of Greater Metropolitan Rio de Janeiro, Brazil, suffered deterioration in the quality of the public water supply, caused by the presence of geosmin, which compromised the water treatment process at the Guandu Water Treatment Plant, the only water source in the region. The phenomenon results from lack of investment in sewage infrastructure in the Guan$d u$ River Basin, which previously affected only the predominantly low-income population. The article aims to identify different social actors' roles and actions, using the Systemic Integration methodology, to allow convergence of their interests for prioritizing and achieving depollution of the Guandu River. Two distinct groups were identified: those who need to collaborate to achieve success with the initiative, consisting of planning, operations, and inspection agencies, and actors capable of politically leveraging and enabling the initiative, namely influential social, political, economic, and media sectors. In conclusion, the water supply crisis may recur seasonally if nothing is done and may thus be the element capable of leading to a convergence of interests among influential sectors for investment in sewage infrastructure to reverse the river basin's degradation, a requirement to solve the water crisis in Rio de Janeiro.

Water Supply; Water Treatment Plants; Sewerage; Public Policy; Social Investiment Project

\section{Resumen}

En enero de 2020, la población de la Región Metropolitana de Río de Janeiro, Brasil, estuvo afectada por un deterioro de la calidad del agua, causada por la presencia de geosmina, que comprometió el proceso de tratamiento de agua de la Estación de Tratamiento de Agua del Guandú, único manantial de esa región. Este fenómeno es consecuencia de la falta de inversión en el alcantarillado sanitario, a lo largo de la cuenca del Río Guandú, que antes afectaba solamente a la población predominantemente de baja renta. El objetivo de este artículo fue identificar el papel y la actuación de los diferentes actores sociales, mediante la adopción de la metodología de integración sistémica, para viabilizar la convergencia de intereses de estos actores, en el sentido de priorizar y concretizar la descontaminación del Río Guandú. Fueron diferenciados dos grupos: aquellos que deben trabajar coordinadamente para el éxito de la empresa, compuesto por todos los órganos de planificación, operación, regulación y fiscalización, y los actores capaces de impulsar politicamente y viabilizar su realización, que son los influyentes sectores sociales, políticos, económicos y mediáticos. Se llegó al compromiso de que la crisis de abastecimiento de agua puede repetirse estacionalmente, en caso de que no se haga nada, y puede ser el elemento capaz de conseguir la nunca antes alcanzada convergencia de intereses de los sectores influyentes para realizar la inversión en infraestructura de alcantarillado sanitario que revierta la degradación de la bahía, requisito para resolver consecuentemente la crisis de agua en Río de Janeiro.

Abastecimento de Agua; Plantas de Tratamiento de Agua; Alcantarillado; Politicas Públicas; Proyetos de Investimientos Social

Recebido em 26/Ago/2020

Versão final reapresentada em 26/Jan/2021

Aprovado em 11/Mar/2021 